\title{
A Comparative Study of the Adsorption of Crystal Violet Dye from Aqueous Solution on Rice Husk and Charcoal
}

\author{
Nafeesa J. Kadhim
}

\author{
Souad A. Mousa* \\ Ahlam M. Farhan
}

\author{
Eman A. Muhammed
}

Received 11/9/2019, Accepted 12/12/2019, Published 18/3/2020

\begin{abstract}
:
In this work, the adsorption of crystal violet dye from aqueous solution on charcoal and rice husk has been investigated, where the impact of variable factors (contact time; the dosage of adsorbent, $\mathrm{pH}$, temperature, and ionic strength) have been studied. It has been found that charcoal and rice husk have an appropriate adsorption limit with regards to the expulsion of crystal violet dye from fluid arrangements. The harmony adsorption is for all intents and purposes accomplished in 45 min for charcoal and 60 min for rice husk. The amount of crystal violet dye adsorbed ( $0.4 \mathrm{~g}$ of charcoal and $0.5 \mathrm{~g}$ of rice husk) increased with an increasing $\mathrm{pH}$ and the value of 11 is the best. The effect of temperature on the adsorption process was studied at the range (298-323) K. The test comes about were broken down by utilizing Freundlich and Tempkin isotherm models, where the Freundlich and Tempkin factors were determined, and it has been found that the adsorption isotherm obey the Freundlich isotherm. The effect of ionic strength on the adsorption process was studied also via sodium chloride electrolyte solution; the results have been revaled that the sodium ion has a positive impact on the adsorption process. The thermodynamic parameters are shown estimated as $\Delta \mathrm{H}$ values were $2.8012 \mathrm{~kJ} \mathrm{~mol}^{-1}$ and $5.8252 \mathrm{~kJ} \mathrm{~mol}^{-1}$ for charcoal and rice husk, respectively; this behavior referred to endothermic adsorption.
\end{abstract}

Key words: Adsorption process, Charcoal, Crystal Violet, Rice Husk, Thermodynamic.

\section{Introduction:}

Various methods have been used to remove the contaminants from the wastewater, like; ion exchange, activated carbon adsorption, membrane technology, and coagulation, degradation and so on, but it has been found that the adsorption process is the superior technique to other processes of removing dyes from aqueous worldwide. Adsorption application follows simple design easy to operate and the obtained results relatively are of high quality (1). Today, scientists have turned out with thinking about that has been centered on the minerlization adsorbents that are chiefly gotten from farming waste and mechanical side-effect since they required small handling and plentiful in nature, so many low-cost natural materials have been investigated as an adsorbent for removing contaminants from wastewater, (2-8). Some minimal effort plant squander had specifically been utilized as an adsorbent for color adsorption from wastewater treatment.

Department of Chemistry, College of Science for Women, University of Baghdad, Baghdad, Iraq

*Corresponding author: souadabdmousa@yahoo.com "ORCID ID: 0000-0001-6333-3417
Nonetheless, the utilization of untreated plant squanders adsorbent can likewise bring a few issues, for example, bring down adsorption limit, higher synthetic oxygen request and natural substance request and also add up to natural carbon due to the discharged of the solvent natural compound contained in the plant material $(9,10)$. A few plants were utilized as adsorbent surfaces to expel a few colors, for example, a novel horticultural (11), malvaparviflora and different plants (12). The crystal violet (CV) dye (Fig.1) is a water- soluble cationic dye (13) and is widely used in textile dyeing. The dye has a brightness and high color intensity, even at low concentration. The CV is easily absorbed by the creatures in the water and affected their lives; therefore the waste water containing crystal violet dye needs to be treated before it is discharged into water bodies (14). The present work involves using plant rice husk and charcoal as a reasonable sorbent for the removal of crystal violet from aqueous solutions and check the freundlich and Temkin isotherms. The thermodynamic parameters and $\mathrm{pH}$ values have been calculated. 
<smiles>[Y]N([Y9])c1ccc(C(c2ccc(N([R])[R])cc2)c2ccc(N([2H])[2H])cc2)cc1</smiles>

Figure 1. Structure of crystal violet dye

\section{Material and Methods:}

\section{Chemicals and Apparatus}

Crystal violet dye was supplied from the HIMEDIA company, rice husk was provided from Al-Najaf Analysis factory, charcoal was provided from (BDH) with purity $99.7 \%$. Hydrochloric acid was provided from BDH with purity $37 \%$ and sodium hydroxide was supplied from Riedel-De Haen AG Seelze-Hannover with purity 99\%.Visible spectrophotometer model 721 - China was used to record absorbance of crystal violet before and after adsorption experiments. Thermostated Shaker water bath model JEIOTECH (BS-11)-Germany was used to shake the aqueous solutions of dye with adsorbents, while Remi Centrifuge model R\&C.Bombay-Japan was utilized to separate the adsorbents from the aqueous solution of dye and pH-mater model Hanna-HI-8417-England was used to adjust the $\mathrm{pH}$ of the solutions.

\section{Absorbed Substance}

The crystal violet dye stock arrangement was set up by dissolving precisely weighted color in refined water to the centralization of $8 \mathrm{ppm}$, was utilized without assist cleansing at $\lambda_{\max }(585 \mathrm{~nm})$, (Fig.2) shows the absorption spectrum of dye. The arrangements were gotten by weakening the color stock arrangement in precise extents to various beginning focuses from (0.4-10 ppm). Figure 3 shows the calibration curve, which was used to convert the absorbance value of dye to concentration According to Beer-Lambert law.

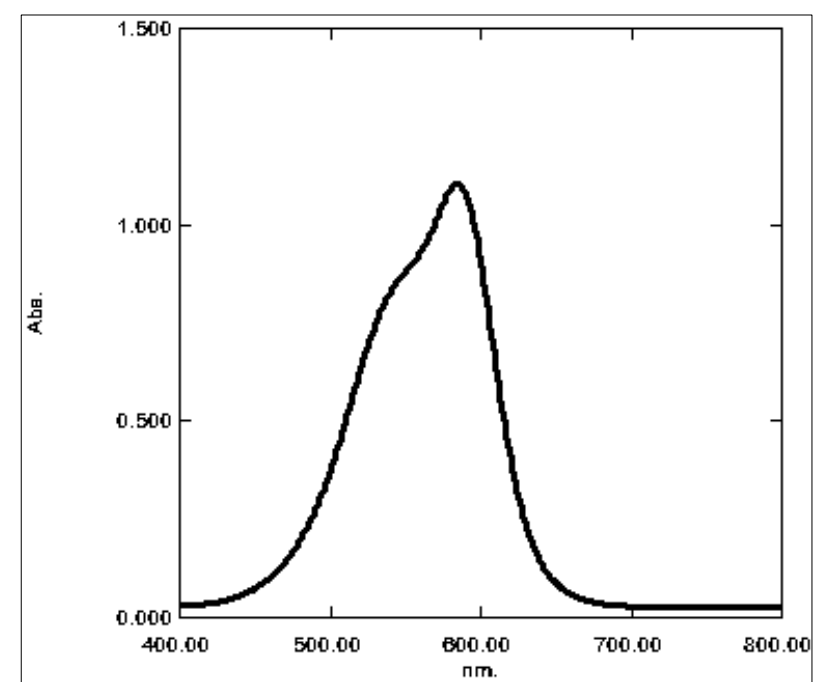

Figure 2. Absorption spectrum of Crystal violet dye

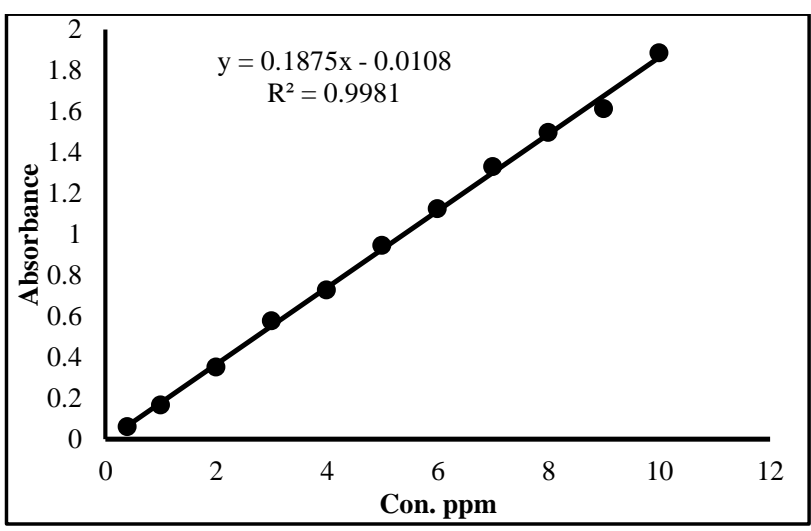

Figure 3. Calibration curve of Crystal violet at 585 nm

\section{Rice Husk}

The dry rice husks were washed with excessive amounts of distilled water, several washings were performed to remove dust and soluble materials. Washed surfaces were then dried under sunlight and in an oven at $105 \mathrm{C}^{\circ}$ for a period of 12 hours and kept in airtight containers. The surfaces were then ground and sieved by using a $75 \mu$ sieve.

\section{Batch Adsorption Experiment}

Group tests were done to decide the impacts of $\mathrm{pH}$, contact time, beginning color focus and adsorbent dosage by differing the factors under examination and saving different factors steady. The feed arrangement was set up by dissolving a precisely measured amount $0.1 \mathrm{~g}$ of strong color in 1liter of water. The exploratory arrangement of wanted focus was acquired by progressive weakening of stock arrangement. The $\mathrm{pH}$ of every one of these arrangements was kept up by including $0.1 \mathrm{~N}$ hydrochloric acid or $0.1 \mathrm{~N}$ sodium hydroxide. The adsorption was observed by deciding the convergence of crystal violet in arrangement a 
utilizing twofold bar Visible spectrophotometer, at $\lambda_{\max } 585 \mathrm{~nm}$. Percentage of color expulsion and amount of crystal violet adsorbed on adsorbent at the season of harmony quantity of dye adsorbed was figured utilizing the following equation (15):

$Q_{e}=\frac{\left(C_{0}-C_{e}\right) V}{W}$

where $\mathrm{C}_{0}$ and $\mathrm{C}_{\mathrm{e}}$ are the primary and the equanimity concentrations $(\mathrm{mg} / \mathrm{l})$ of dye, respectively. $\mathrm{Q}_{\mathrm{e}}$ is the quantity of dye adsorbed on the adsorbent at the time of equanimity $(\mathrm{mg} / \mathrm{g}), \mathrm{V}$ is volume (l) of solution and $\mathrm{W}$ is the mass of adsorbent (g).

\section{Influence of Variable Factors}

Contact time: Adsorption equilibrium studies are performed with an adsorbent quantity of $0.5 \mathrm{~g}$ and $0.4 \mathrm{~g}$ of Charcoal and Rice husk, respectively by 25 $\mathrm{ml}$ of dye and concentration 8ppm with different intervals time $(15,30,45,60,75,90,105$, and 120) $\min$ at $25^{\circ} \mathrm{C}$.

Dosage of adsorbent: Initial of adsorbent dose 0.1, $0.2,0.3,0.4$ and $0.5 \mathrm{~g}$. Contact time $60 \mathrm{~min}$, agitation speed $300 \mathrm{rpm}$, concentration $8 \mathrm{ppm}$, and temperature $25^{\circ} \mathrm{C}$.

$\boldsymbol{p H}$ : Adsorption tests were done at $\mathrm{pH} 1,3,5,9$ and 11 at $25^{\circ} \mathrm{C}$ with $25 \mathrm{ml}$ of a color focus $8 \mathrm{ppm}$. The acidic and basic $\mathrm{pH}$ of the media was adjusted by using hydrochloric acid $0.1 \mathrm{M}$ and sodium hydroxide $0.1 \mathrm{M}$.

Temperature: The adsorption tests were performed at four temperatures $(25,35,45$ and 55$){ }^{\circ} \mathrm{C}$ in an indoor regulator joined with a shaker. The examinations were done by taking $25 \mathrm{ml}$ of crystal violet arrangement with various beginning convergences of colors ranging of (4 - 8) ppm.

Ionic strength: Adsorption tests were conveyed different concentrations of $\mathrm{NaCl}(0.1,0.01$ and $0.001) \mathrm{M}$ at $25^{\circ} \mathrm{C}$ with $25 \mathrm{ml}$ of dye concentration 8ppm.

\section{Results and Discussion: Adsorbent Dosage}

The adsorbent dosage is an imperative parameter in the adsorption process; the experiments were done by using different amounts of the charcoal and rice husk for a given initial concentration of dye solution $8 \mathrm{ppm}$ at $25^{\circ} \mathrm{C}$. Figure 4 shows the effect of dosage of charcoal and rice husk on the adsorption capacity of crystal violet dye.

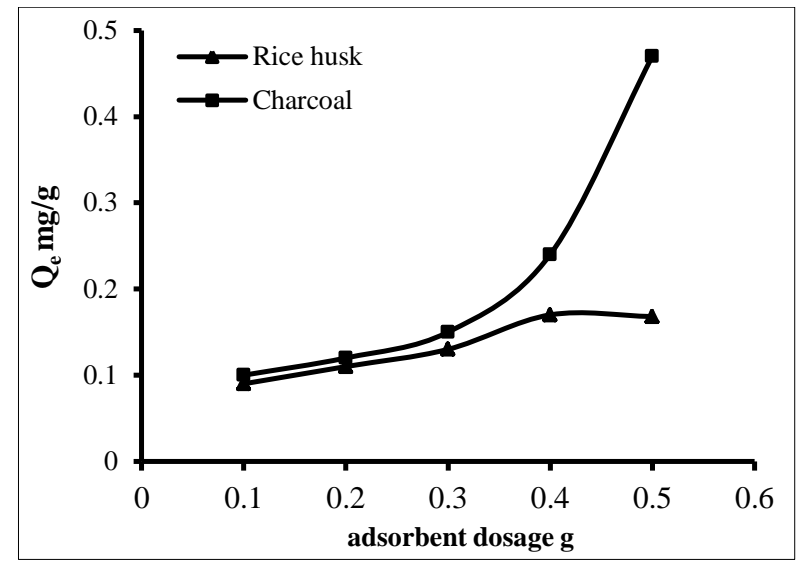

Figure 4. The effect of adsorbents dosage on the adsorption of crystal violet.

It is clear that the $\mathrm{Q}_{\mathrm{e}}$ of the color increments with the expansion in adsorbent measurements, however an estimation of 0.5 and $0.4 \mathrm{~g}$ for charcoal and rice husk respectively. The rate evacuation comes to right around the greatest esteem. This is most likely because of the more prominent accessibility of the replaceable destinations or the expanded surface territory where the adsorption happens (16).

\section{Equanimity Time}

The effect of contact time on the amount of crystal violet adsorbed per unit of adsorbent was investigated under $25^{\circ} \mathrm{C}$ at dye concentration of $8 \mathrm{ppm}$ and used the optimum values of adsorbents $(0.5$ and $0.4 \mathrm{~g}$ for charcoal and rice husk respectively). Figure 5 shows the results of equilibrium time for crystal violet on charcoal and rice husk.

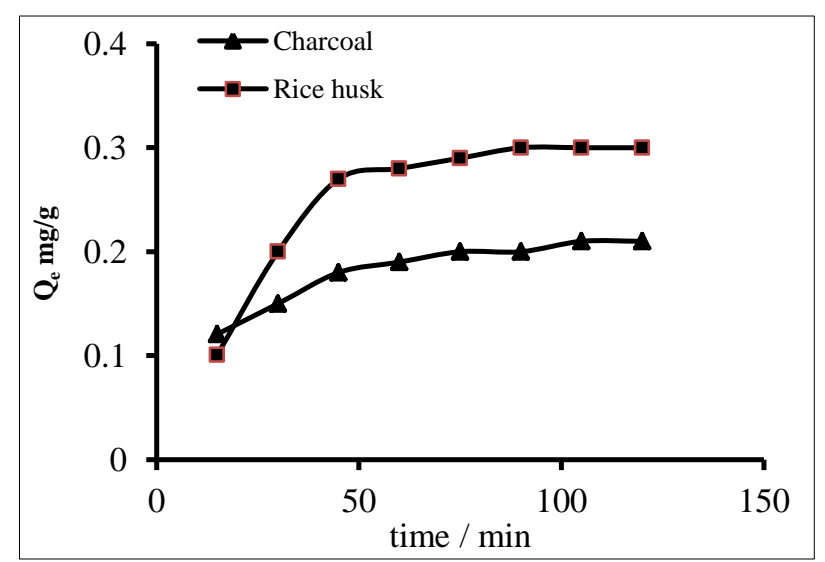

Figure 5. The effect of contact time on the adsorption of crystal violet dye on charcoal and rice husk

It can be observed that the adsorption process exhibits immediate rapid adsorption and reaches equilibrium within a short period of $45 \mathrm{~min}$ for charcoal and $60 \mathrm{~min}$ for rice husk (16). 


\section{The Effect of $\mathrm{pH}$}

Figure 6 demonstrates the take-up of crystal violet dye expanded with diminishing starting $\mathrm{pH}$ and was the best at $\mathrm{pH} 11$. At low $\mathrm{pH}$ esteems the practical gatherings of charcoal and rice husk would be protonated and result in a more grounded fascination for adversely charged particles in the adsorption medium. The $\mathrm{pH}$ basically influences the level of ionization of the crystal violet and the surface properties of charcoal and rice husk.

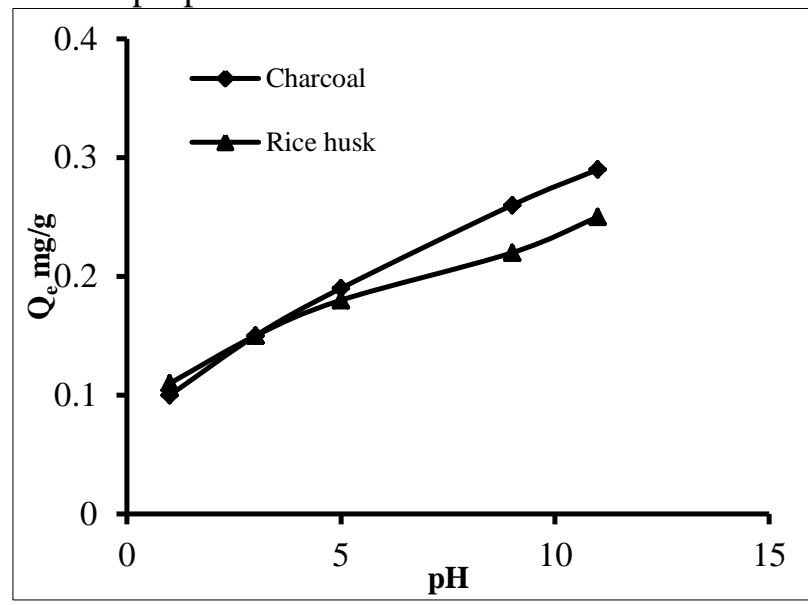

Figure 6. Effect of $\mathrm{pH}$ on the removal of crystal violet dye on charcoal and rice husk.

As appeared in Fig. 6 that, the adsorption of cationic crystal violet dye was increased with expanded the $\mathrm{pH}$. It can be noticed that the best adsorption was at $\mathrm{pH} 11$ as the surfaces of the adsorbents become negatively charge and resultantly high interaction between the dye and the surface of the adsorbents. The low adsorption of crystal violet adsorption under acidic may be correlated with lyophobic behavior between adsorbate and adsorbents and resultantly, the forces between adsorbate and adsorbent may change (17).

\section{Effect of Ionic Strength}

Figures 7 and 8 demonstrate the expanded evacuation of crystal violet dye at $8 \mathrm{ppm}$ on the charcoal and rice husk surface when sodium chloride $(\mathrm{NaCl})$ is included at the optimum values ( $0.5 \mathrm{~g}$ of charcoal and $0.4 \mathrm{~g}$ of rice husk), (contact time; $45 \mathrm{~min}$ for charcoal and $60 \mathrm{~min}$ for rice husk) and at $\mathrm{pH}$ 11. It can be explained that the cationic sodium ions increase the capability of the interaction of the dye on the surface of the adsorbents, keeping in mind the end goal to the way that the extra gathering of sodium chloride courses of action reason a development in competition between particles of the crystal violet and electrolyte particles on the expulsion goals at first look (18).

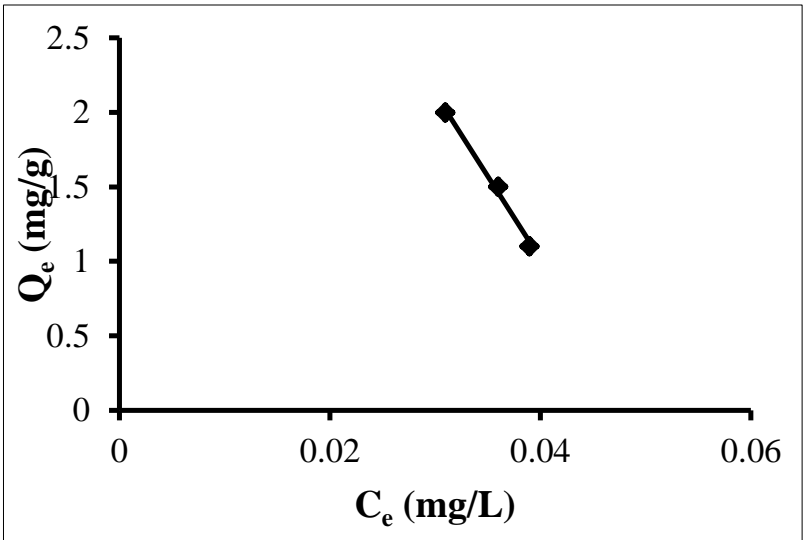

Figure 7. Effect of ionic strength on removal of crystal violet dye on charcoal at $298 \mathrm{~K}$.

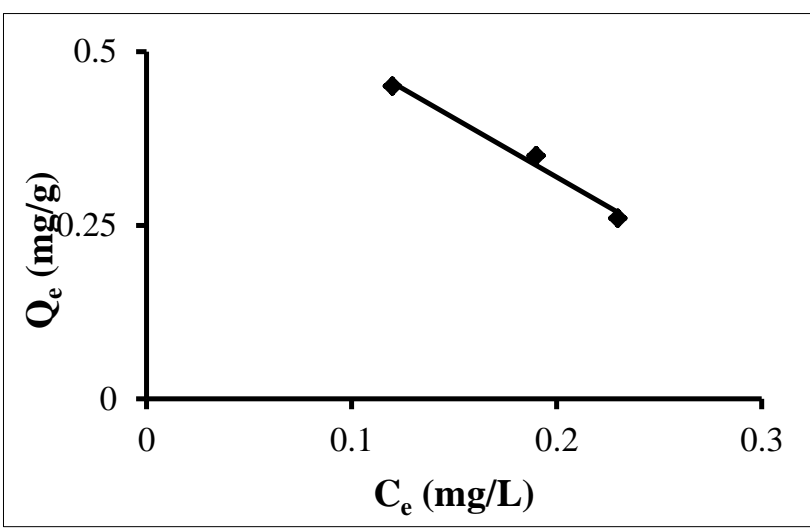

Figure 8. Effect of ionic strength on the removal of crystal violet dye on rice husk at $298 \mathrm{~K}$.

\section{Adsorption Isotherms}

Adsorption properties and balance parameters, normally known as adsorption isotherms, which show how the adsorbate interfaces with adsorbents, and complete comprehension of the idea of cooperation. Tow famous isotherm, the Freundlich and Temkin were examined. The Freundlich isotherm was utilized for the adsorption of crystal violet on the adsorbents. The Freundlich isotherm was calculated by the following equation: (19)

$$
\log Q_{e}=\log K_{f}+1 / n \log C_{e}
$$

where $\mathrm{Q}_{\mathrm{e}}$ is the measure of crystal violet dye adsorbed $(\mathrm{mg} / \mathrm{g}), \mathrm{C}_{\mathrm{e}}$ is the balance grouping of color in the arrangement $(\mathrm{mg} / \mathrm{l}), \mathrm{K}_{\mathrm{f}}$ and $1 / \mathrm{n}$ are constants fusing the elements influencing the adsorption limit and force of adsorption, separately. 

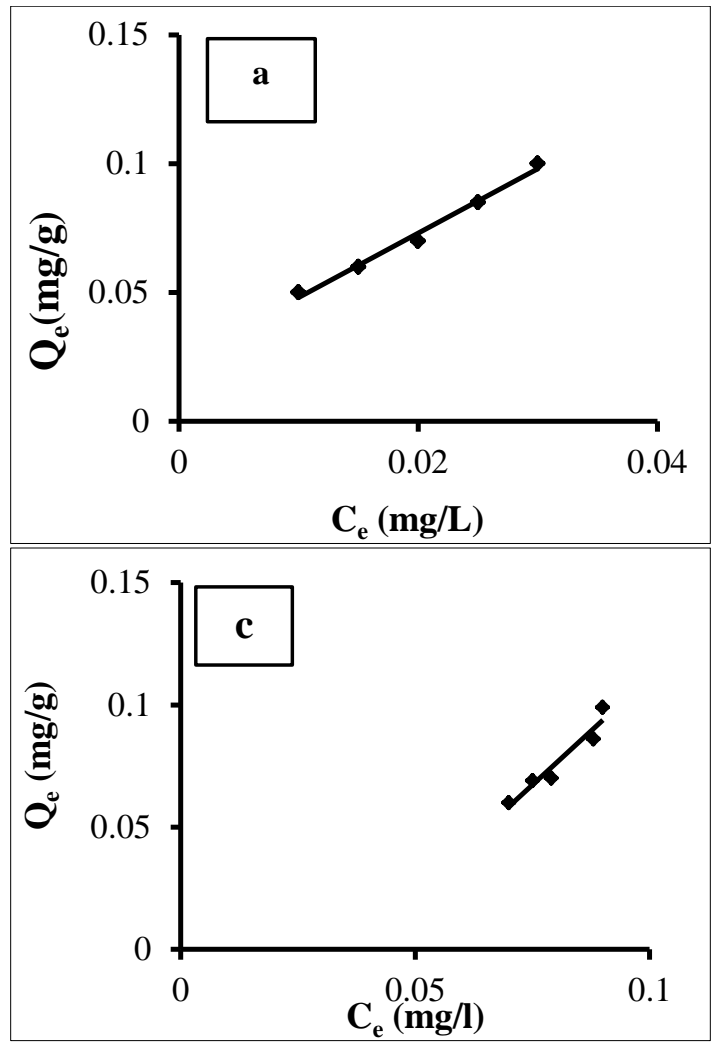
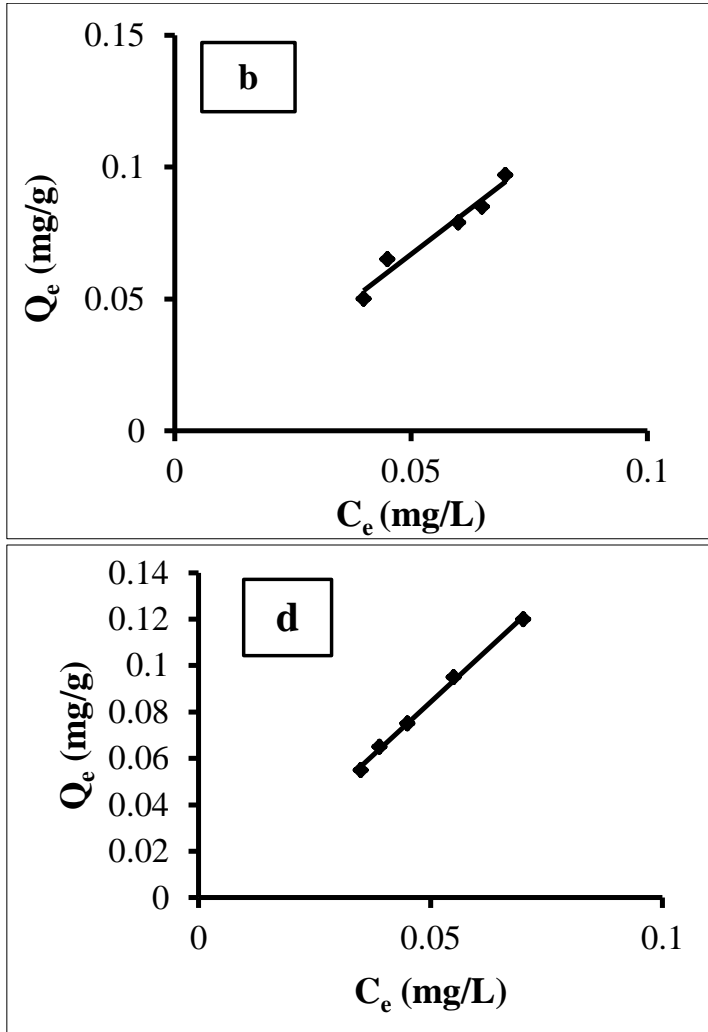

Figure 9. Adsorption isotherms of Crystal Violet dye on Charcoal at a temperature range: a) 298, b) 308 , c) 318 and d) $328 \mathrm{~K}$.
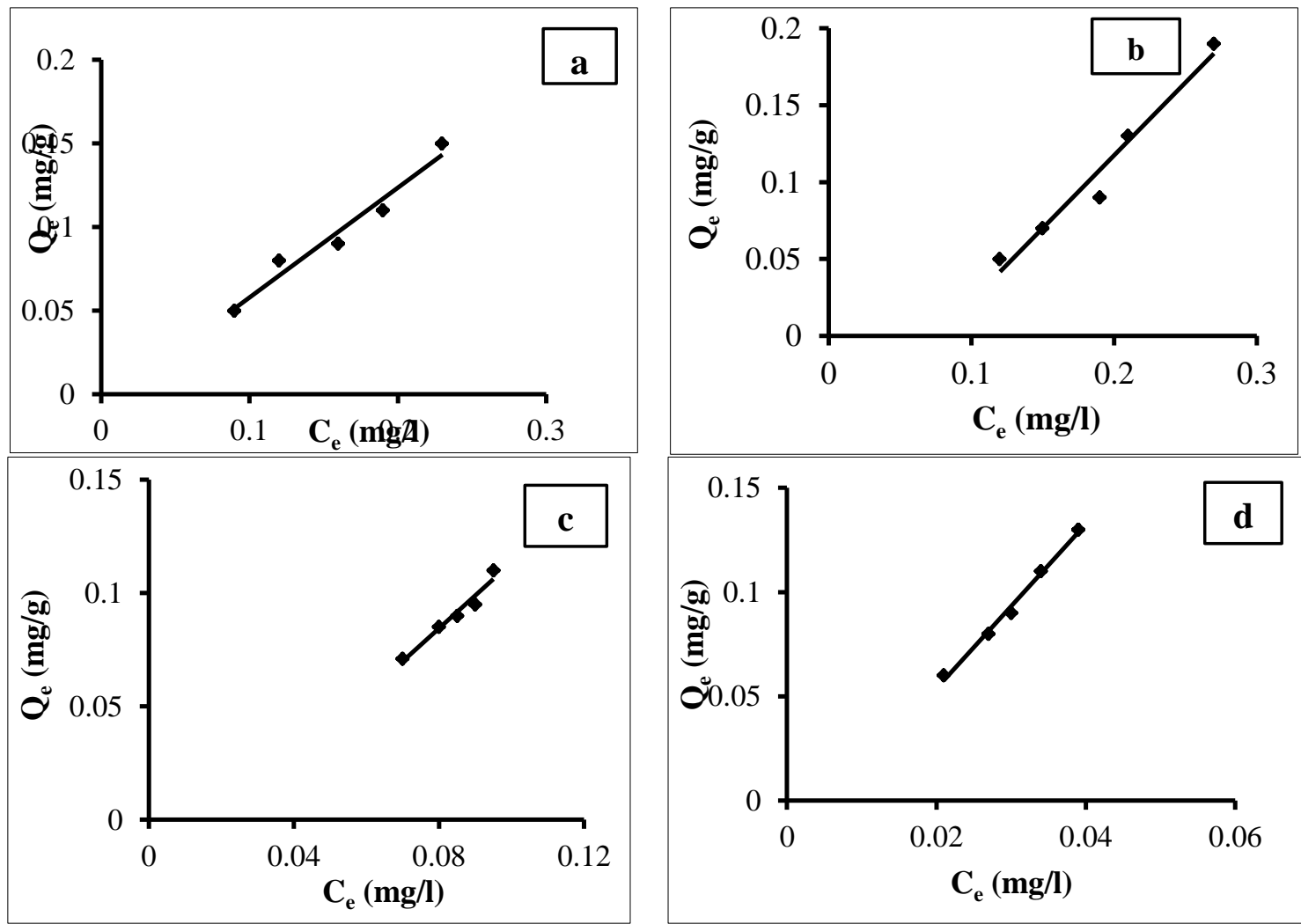

Figure 10. Adsorption isotherms of crystal violet dye on rice husk at a temperature range: a) 298 b) 308, c) 318 and d) $328 \mathrm{~K}$.

Figures 9 and 10 demonstrate the adsorption isotherm of S-type, which show that the adsorbent potentially has a high vitality of adsorption (20). Likewise, this shows a vertical or level introduction of adsorbate, and the adsorbate is mono practical. Temkin and Pyzhev considered the impacts of some circuitous sorbate/adsorbate cooperations on adsorption isotherms and proposed 
that in view of these connections the warmth of adsorption of the considerable number of particles in the layer would diminish directly with scope. The Temkin isotherm has been utilized following form (21):

$Q_{e}=B_{T} \ln K_{T}+B_{T} \ln C_{e}$

where $\mathrm{K}_{\mathrm{T}}$ and $\mathrm{B}_{\mathrm{T}}$ is the equilibrium binding constant $(1 / \mathrm{g})$
As appeared from Figures 11,12,13, and 14 with the calculated results in Table (1) and (2) that, the estimations of $\mathrm{R}^{2}$ coefficient were near to be 1 , for both isotherms, which means that there is a good corresponding in the relationship between $\mathrm{Q}_{\mathrm{e}}$ and $\ln$ $\mathrm{C}_{\mathrm{e}}$ at different temperatures which showing the helpful estimations of its constants. The adsorption isotherm for is clarified better by Freundlich isotherm demonstrates.

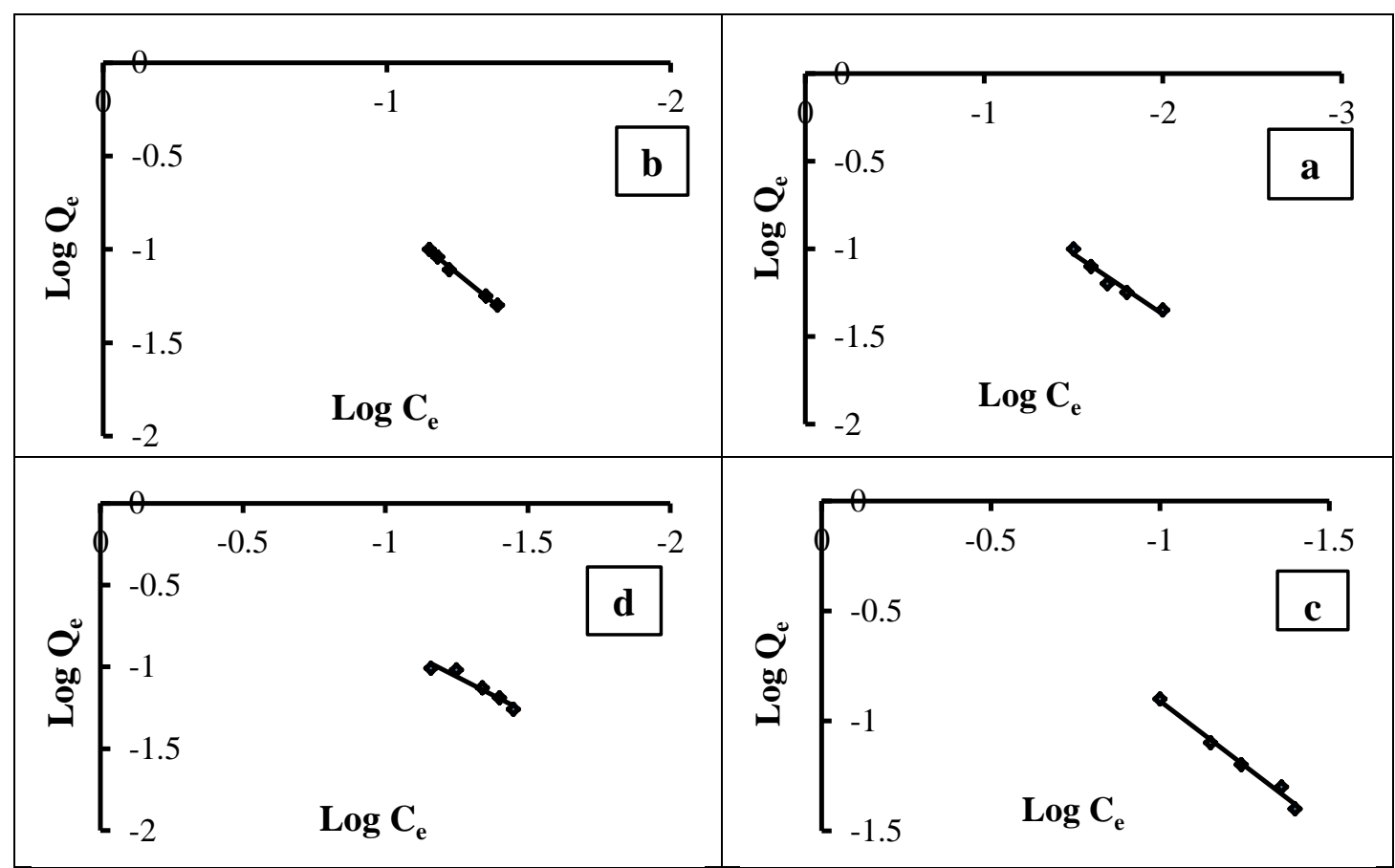

Figure 11. Freundlich Linear relationship between $\log Q_{e}$ and $\log C_{e}$ for crystal violet dye on charcoal at a temperature range: a) 298 b) 308 , c) 318 and d) $328 \mathrm{~K}$.

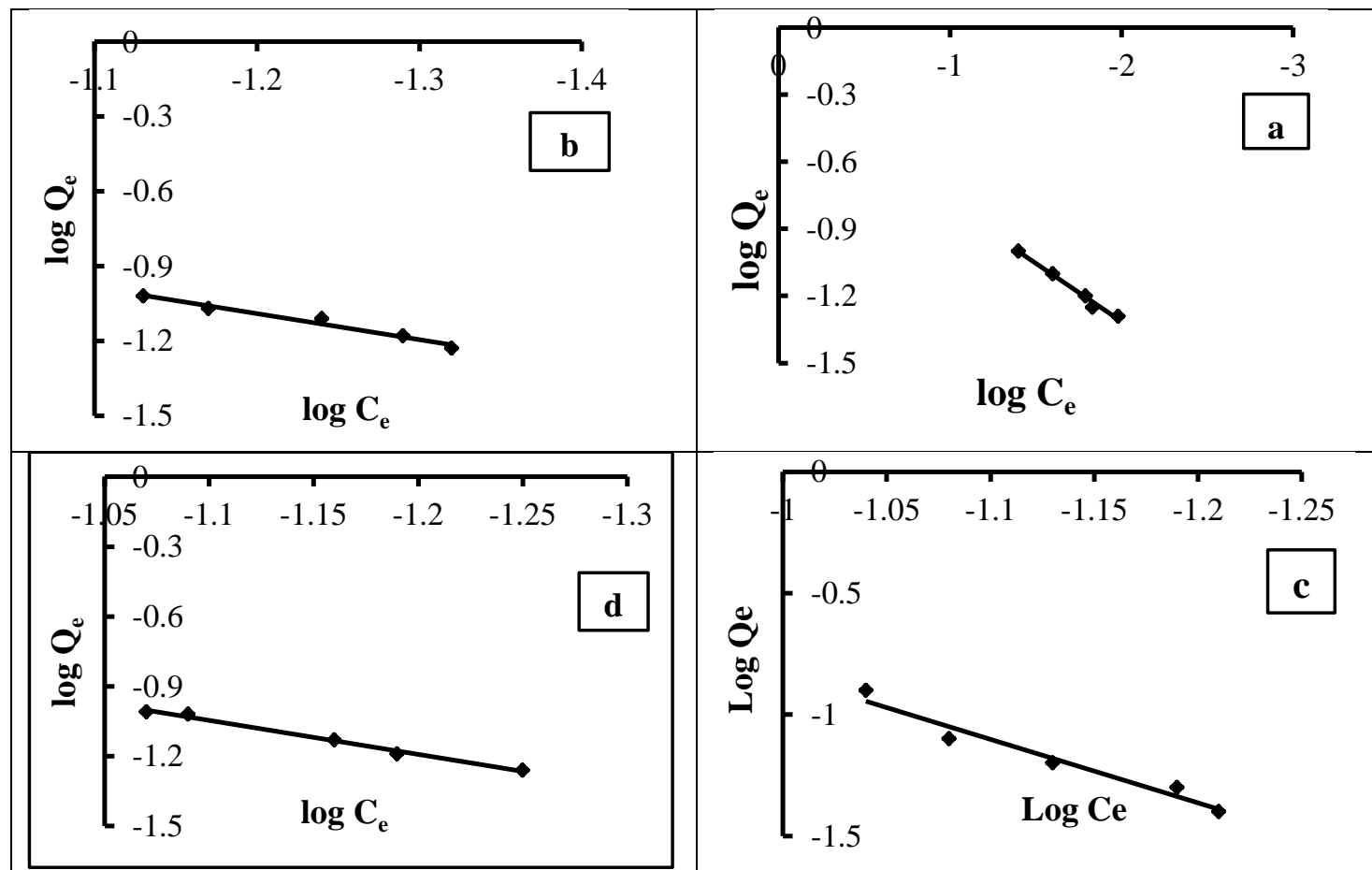

Figure 12. Freundlich Linear relationship between $\log Q_{e}$ and $\log C_{e}$ for crystal violet dye on rice husk at a temperature range: a) 298 b) 308 , c) 318 and d) $328 \mathrm{~K}$. 

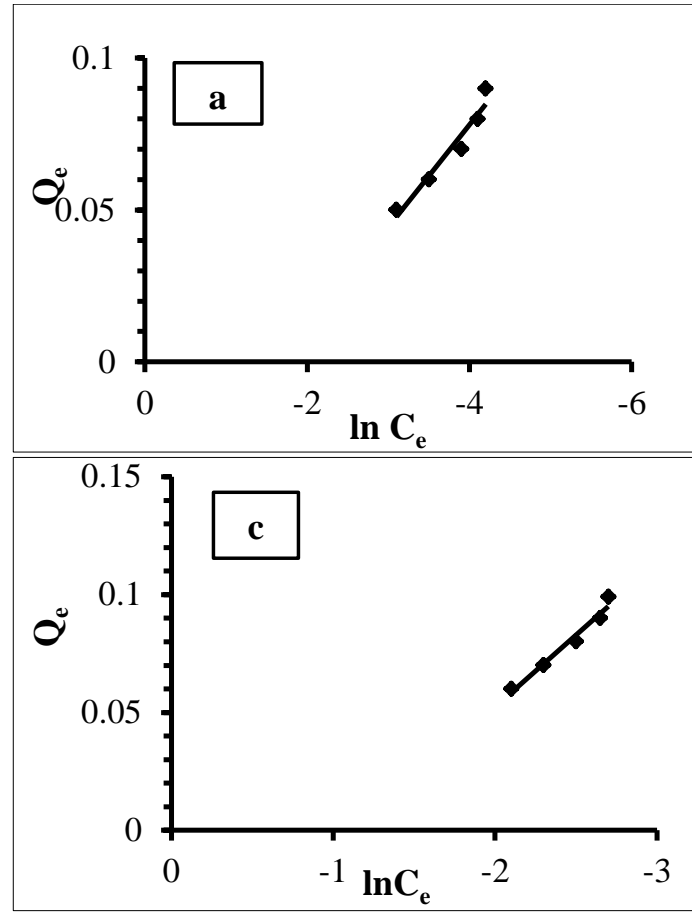
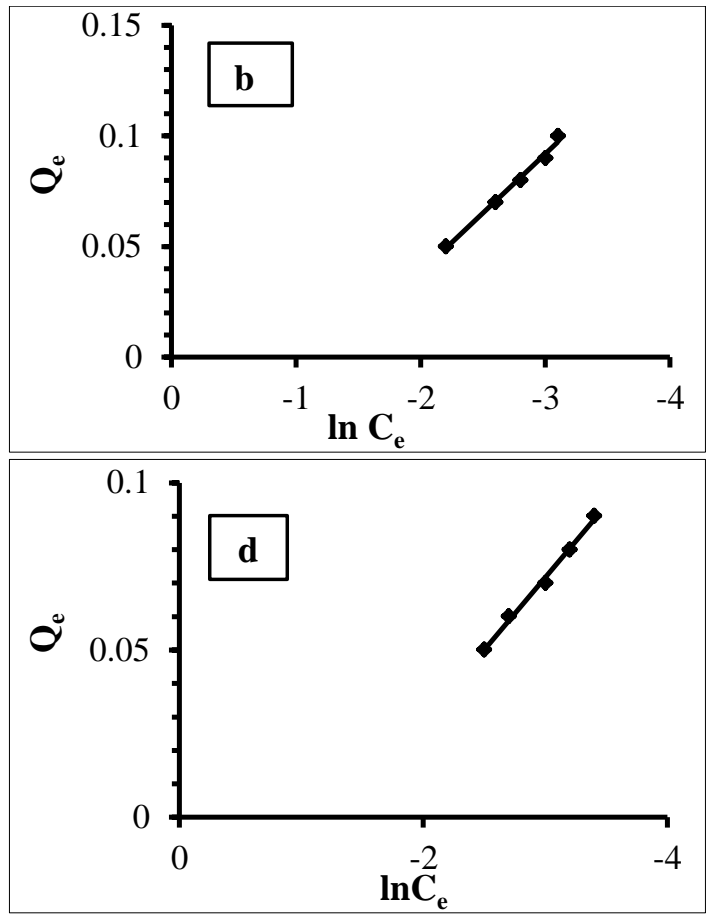

Figure 13. Temkin Isotherm relationship between $Q_{e}$ and $\ln C_{e}$ for crystal violet dye on charcoal at a temperature range: a) 298 b) 308, c) 318 and d) 328 .
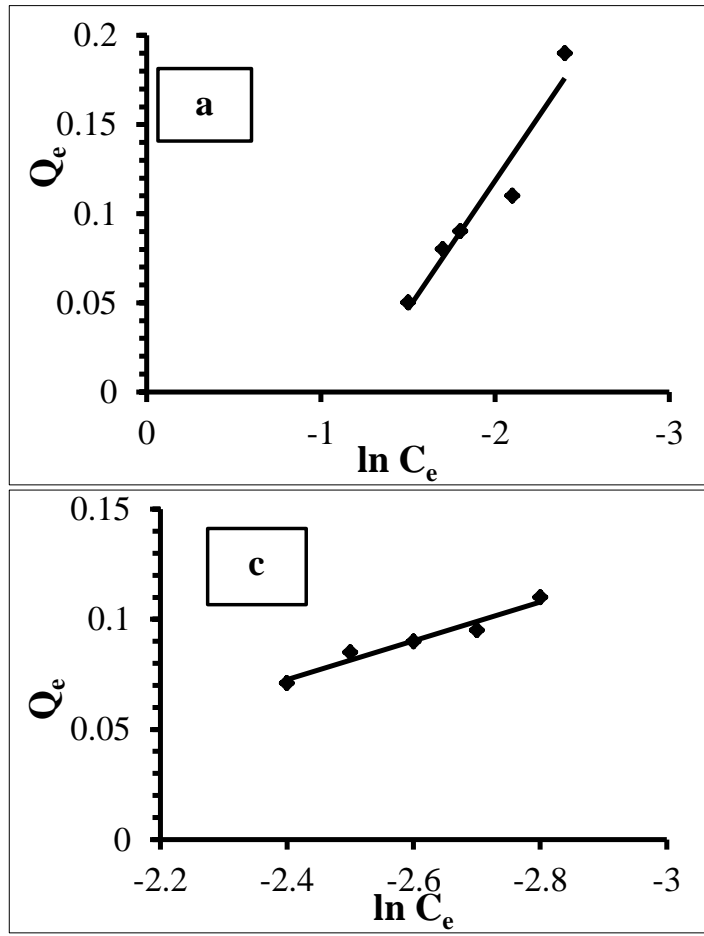
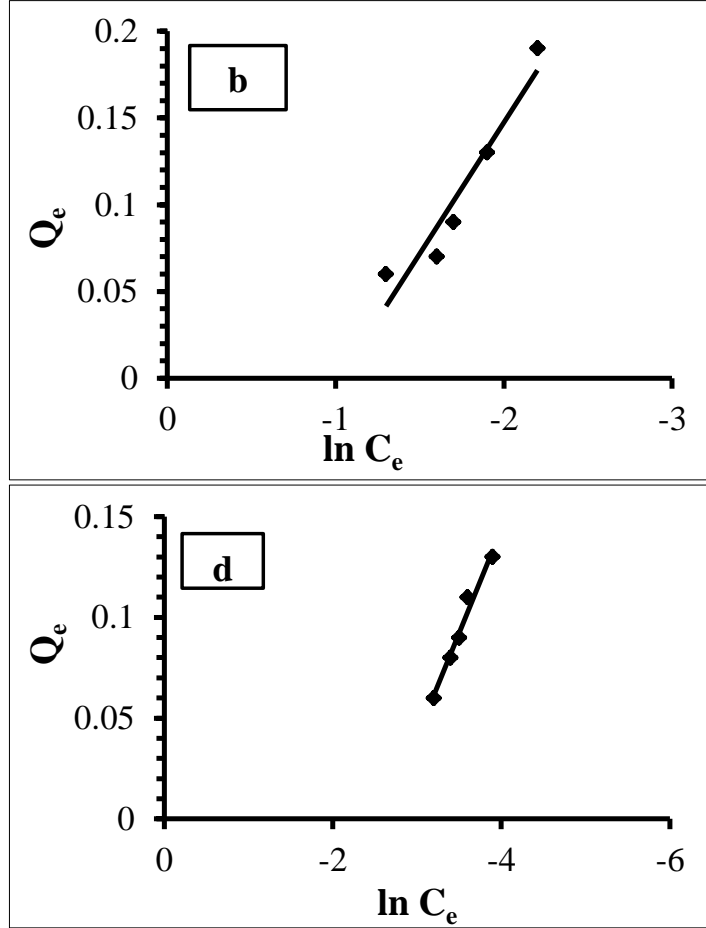

Figure 14. Temkin Isotherm relationship between $Q_{e}$ and $\ln C_{e}$ for crystal violet dye on rice husk at a temperature range: a) 298 b) 308, c) 318 and d) $328 \mathrm{~K}$

Table 1. The factors of Freundlich and Temkin condition for the adsorption of crystal violet dye on charcoal

\begin{tabular}{ccccccc}
\hline \multicolumn{3}{c}{ Freundlich factors } & \multicolumn{3}{c}{ Temkin factors } \\
\hline $\mathrm{T}$ & $\mathrm{R}^{2}$ & $\mathrm{n}$ & $\mathrm{K}_{\mathrm{f}}$ & $\mathrm{R}^{2}$ & $\mathrm{~K}_{\mathrm{f}}$ & $\mathrm{B}_{\mathrm{T}}$ \\
298 & 0.9561 & 1.4586 & 0.9952 & 0.9432 & 0.8780 & 0.0337 \\
308 & 0.9947 & 0.8152 & 2.5305 & 0.9908 & 0.8539 & 0.0535 \\
318 & 0.9876 & 0.8484 & 1.8612 & 0.9682 & 0.8517 & 0.061 \\
328 & 0.9336 & 1.1152 & 1.1524 & 0.9944 & 0.8749 & 0.0432 \\
\hline
\end{tabular}


Table 2. The factors of Freundlich and Temkin condition for the adsorption of crystal violet dye on rice husk

\begin{tabular}{lllllll}
\hline \multicolumn{3}{c}{ Freundlich factors } & \multicolumn{3}{c}{ Temkin factors } \\
\hline $\mathrm{T}$ & $\mathrm{R}^{2}$ & $\mathrm{n}$ & $\mathrm{K}_{\mathrm{f}}$ & $\mathrm{R}^{2}$ & $\mathrm{~K}_{\mathrm{f}}$ & $\mathrm{B}_{\mathrm{T}}$ \\
298 & 0.9848 & 1.9198 & 0.5344 & 0.9324 & 0.6767 & 0.144 \\
308 & 0.9703 & 0.9620 & 1.1693 & 0.9176 & 0.6994 & 0.1513 \\
318 & 0.9564 & 0.3815 & 1.1998 & 0.9551 & 0.7268 & 0.088 \\
328 & 0.9917 & 0.6843 & 3.6425 & 0.9734 & 0.5399 & 0.103 \\
\hline
\end{tabular}

\section{Thermodynamic Parameters}

The thermodynamics factors identified with the adsorption of color. For example, enthalpy change, entropy change and Gibbs free energy change $\Delta \mathrm{G}^{\mathrm{o}} . \Delta \mathrm{H}^{\mathrm{o}}$ has been computed for all adsorption forms, as indicated by Van't Hoff equation 6 by means of plotting of the adsorption equilibrium constant $\left(\mathrm{K}_{\mathrm{eq}}\right)$ as $\left(\ln \mathrm{Q}_{\mathrm{e}} / \mathrm{C}_{\mathrm{e}}\right)$ against the temperature as (1/T) (22). The outcomes are recorded in Table 3 and Fig. 15 and 16.

$\Delta G^{\circ}=-R T \ln K$

$\ln K_{e q}=\frac{-\Delta H}{R T}+\frac{\Delta S^{\circ}}{R}$

where $\mathrm{K}_{\mathrm{eq}}$ is adsorption equilibrium constant and $\mathrm{R}$ is the gas constant.

Table 3. Thermodynamic parameters of crystal violet dye adsorption on charcoal and rice husk.

\begin{tabular}{|c|c|c|c|c|c|c|}
\hline \multicolumn{4}{|c|}{ Charcoal } & \multicolumn{3}{|l|}{ Rice Husk } \\
\hline T K & $\Delta H$ k.J.mol ${ }^{-1}$ & $\Delta G$ k.J.mol ${ }^{-1}$ & $\Delta S$ k.J.mol ${ }^{-1}$ & $\Delta H$ k.J.mol ${ }^{-1}$ & $\Delta G$ k.J.mol & $\Delta S$ k.J.mol ${ }^{-1}$ \\
\hline 298 & 2.8012 & 7.730 & -0.035 & 5.8252 & 5.228 & -0.037 \\
\hline 308 & & 9.244 & -0.039 & & 6.402 & -0.039 \\
\hline 318 & & 10.073 & -0.041 & & 7.720 & -0.043 \\
\hline 328 & & 10.935 & -0.042 & & 10.85 & -0.051 \\
\hline
\end{tabular}

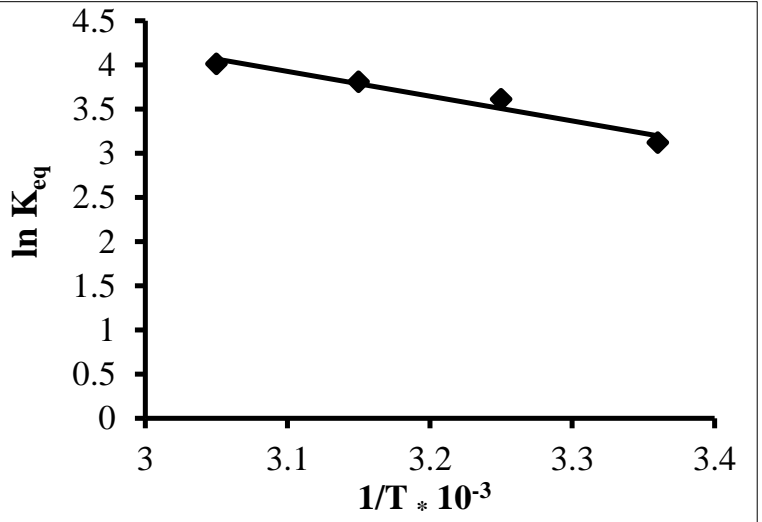

Figure 15. Van't Hoff plot adsorption of crystal violet dye on charcoal.

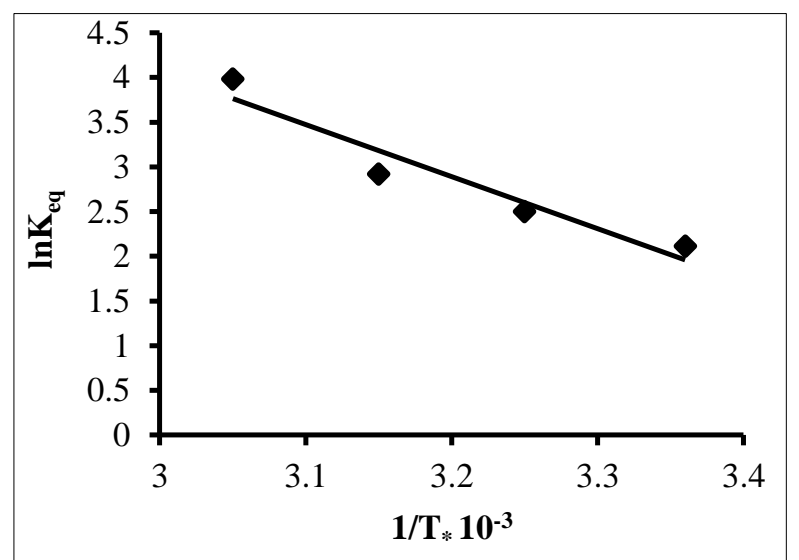

Figure 16. Van't Hoff plot adsorption of crystal violet dye on rice husk.
The adsorption of color increments quickly with an expansion in temperature. The expansion in adsorption limit of charcoal and rice husk was attributed to the development of pore size and initiation of the sorbent surface with temperature. Additionally ascend in temperature builds the versatility of the vast color particles and decreases the swelling impact in this manner empowering the substantial color atom to enter encourage (23). The positive estimation of $\Delta \mathrm{H}$ shows that the adsorption of crystal violet dye onto charcoal and rice husk is an endothermic response. It can be noticed from $\Delta H$ values that the force driving the adsorption process is physics-sorption process.All estimations of $\Delta \mathrm{G}$ values released that the adsorption procedure went with the procedure of assimilation, where the adsorbed particles spread inside the pores of the charcoal and rice husk and expands speed of organization with expanding temperature this conduct is inferable from extra assimilation. The negative values of $\Delta \mathrm{S}$ indicate that the regularity of the dye particles on the surface more than they are in the solution and it was higher in charcoal than in rice husk.

\section{Conclusions:}

The adsorption of crystal violet by charcoal and rice husk has been studied. The adsorption was considered as an element of adsorbent 
measurements, contact time, $\mathrm{pH}$, temperature and ionic quality, it has been found that the optimum values of the adsorbents were 0.5 and $0.4 \mathrm{~g}$ for charcoal and rice husk respectively, while the solutions get rapid adsorption and reaches equilibrium within of $45 \mathrm{~min}$ for charcoal and 60 min for rice husk, furthermore the best media for the adsorption process was at $\mathrm{pH} 11$, in addition, the ionic strength was examined and it has been shown a positive effect on the adsorption process. The balance information fit with Freundlich and Tekmin equations of adsorption and the straight relapse factors $\mathrm{R}^{2}$ was utilized to clarify the best fitting isotherm demonstrate. Diverse thermodynamic factors, similar to $\Delta \mathrm{G}^{\mathrm{o}}$ vitality, $\Delta \mathrm{H}^{\mathrm{o}}$ and $\Delta \mathrm{S}^{\mathrm{o}}$ of the on-going adsorption operation have additionally been assessed. The thermodynamic examinations of the color adsorption on charcoal and rice husk store demonstrated that the framework was endothermic in nature.

\section{Conflicts of Interest: None.}

\section{References}

1. Haik Y, Qadri S, Ganoe A, Ashraf S, Sawafta R. Phase change material for efficient removal of crystal violet dye. J. Hazard.. 2010 April 15;176(1-3):11101112.

2. Sulyman M, Namiesnik J, Gierak A. Low-cost adsorbents derived from agricultural byproducts/wastes for enhancing contaminant uptakes from wastewater: A Review. Pol. J. Environ. Stud. 2017; 26 (2):479-510.

3. Bertolini TCR., Izidoro JC, Magdalena CP, Fungaro DA. Adsorption of crystal violet dye from aqueous solution onto Zeolites from coal fly and bottom ashes. Electron. J. Chem. 2013;5 (3):179-191.

4. Fungaro DA, Borrely S, Ivone S, Higa. Removal of color from industrial effluents by adsorption using unmodified and surfactant - modified zeolite from cyclone ash. Periodico Tche Quimica. 2014 Sep;11(22):7-14.

5. Yagub MT, Sen TK, Afroze S, Ang HM. Dye and its removal from aqueous solution by adsorption: a review. Adv. Colloid and Interface Sci. 2014 July; 209:172-184.

6. Sadegh H, Mazloumbilandi M, Chahardouri M. Handbook of Ecomaterials. Springer link, 2017. Lowcost materials with adsorption performance; 1-33.

7. Crini G, Lichtfouse E, Wilson LD, Morin-Crini N. Adsorption-oriented processes using conventional and non-conventional adsorbents for wastewater treatment. InGreen Adsorbents for Pollutant Removal 2018 (pp. 23-71). Springer, Cham..
8. Kalebaila K, Maseka KJ, Mbulo M. Selected adsorbents for removal of contaminants from wastewater: towards engineering clay minerals. Open Journal of Applied Sciences, 2018 Jan;8(8):355-369.

9. Tripathi A, Ranjan MR. Heavy metal removal from wastewater using low cost adsorbents. J Bioremed Biodeg.2015 Jan;6 (6):315.

10. Nasuha N, Zurainan HZ, Maarof HI, Zubir NA, Amri N. Effect of cationic and anionic dye adsorption from aqueous solution by using chemically modified papaya seed. IPCBEE. 2011;8:50- 54.

11. Hameed BH, Krishni RR, Sata SA. Anovel agricultural waste adsorbent for the removal of cationic dye from aqueous solution, J. Hazard. Mater 2009 Feb15;162 (1):305- 311.

12. Farhan AM, Jassim RA, Kadhim NJ. The removal of zinc from aqueous solution using malvaparviflora. J. Baghdad Sci. 2016;13 (3):482- 488.

13. Singh B, Walia BS, Arora R. Parametric \& kinetic study for the adsorption of crystal violet dye by using carbonized eucalyptus, IJCER 2018 Sep; 8 (9):01-11.

14. Kusumastuti E, Santosa SJ. Adsorption of crystal violet dye using zeolite a synthesized from coal fly ash. Mater. Sci. Eng. . 2017;172:1-8.

15. Aljeboree AM, Alshirifi AN, Alkaim AF. Kinetics and equilibrium study for the adsorption of textile dyes on coconut shell activated carbon. Arab. J. Chem.2017 May;10(2):S3381-S3393.

16. Fatiha M, Belkacem B. Adsorption of methylene blue from aqueous solutions using natural clay. J. Mater. Environ. Sci. 2016;7 (1):285-292.

17. Hamaza MO, Kareem SH. Adsorption of direct yellow 4 dye on the silica prepared from locally available available sodium silicate.Eng. and Tech. J . 2012;30 (15):2609- 2625.

18. Pathania D, Sharma S, Singh P. Removal of methylene blue by adsorption onto activated carbon developed from Ficus carica bast. Arabian J. Chem. 2017 Feb;10 (1):S1445-S1451.

19. Baskaran PK, Venkaramen BR, Arivoli S. Adsorption of malachite green dye and by acid activated carbon, kinetic thermodynamic and equilibrium studies. EJ Chem .2011;8 (1):9-18.

20. Cutcheon M. Detergents and Emulsifiers. Allied Publishing Co. New Jersey. 2002.

21. Huarg R,Wang B, Yang B, Zheng D, Zhang Z. Equilibrium, kinetic and thermodynamic studies of adsorption of $\mathrm{Cd}$ (II) from aqueous solution onto HACC-bentonite. Desalination. 2011 Oct 3;280 (13):297-304.

22. Mahmood ZA. Adsorption study for trifluralin on iraqi zeolite, ANJS.2012 Dec;15(4):31-37.

23. Cazetta AL, Vargas AM, Nogami EM, Kunita MH, Guilherme MR, Martins AC, et al. $\mathrm{NaOH}$-activated carbon of high surface area produced from coconut shell: Kinetics and equilibrium studies from the methylene blue adsorption. Chem. Eng. J. 2011 Oct15;174 (1):117-125. 
دراسة عملية الامتزاز لصبغة الكرستال البنفسجية من محاليلها المائية باستخدام قثور الرز والفحم النشط كسطوح مازة ; دراسة من مدالبة مقارنة

احلام محمد فرحان
ايمان عدنان محمد

\author{
سعاد عبد موسى
}

نفيسة جبار كاظم

قسم الكيمباء ، كلية العلوم للبنات، جامعة بغداد، بغداد، العراق.

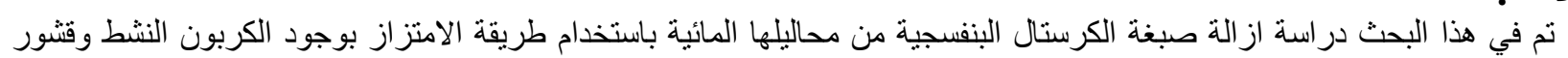

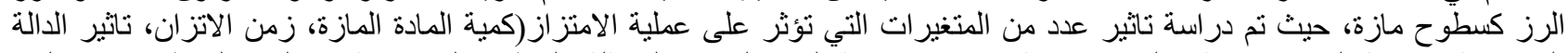

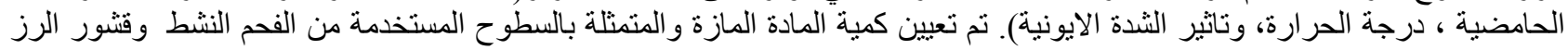

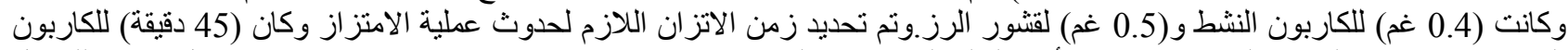

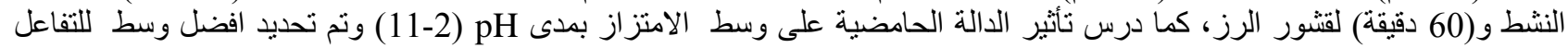

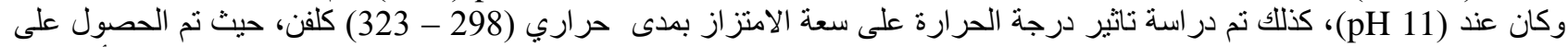

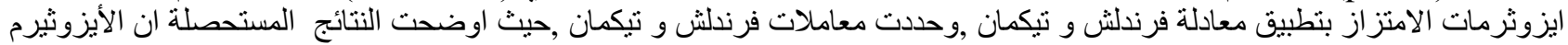

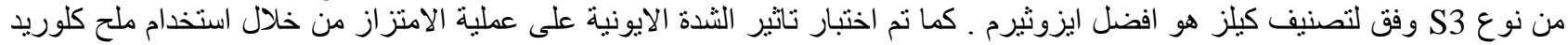

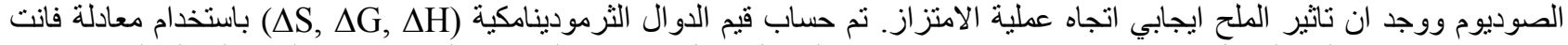

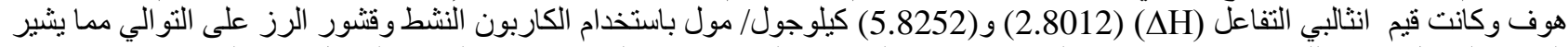

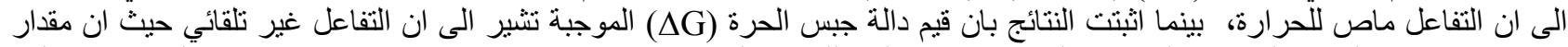

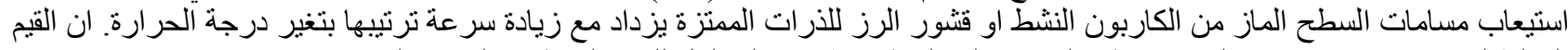

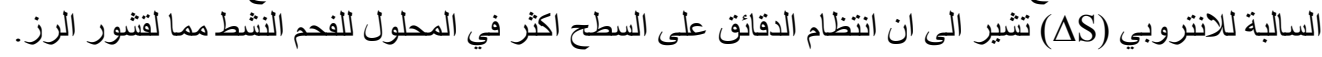

الكلمات المفتاحية: الامتزاز، الثرموداينمك، الفحم، صبغة الكرستال البنفسجية، قثور الرز. 